\title{
ACCOUNTING FOR RECENT DECLINES IN EMPLOYMENT RATES AMONG THE WORKING-AGED DISABLED
}

\author{
John Bound \\ Timothy Waidmann \\ Working Paper 7975 \\ http://www.nber.org/papers/w7975 \\ NATIONAL BUREAU OF ECONOMIC RESEARCH \\ 1050 Massachusetts Avenue \\ Cambridge, MA 02138 \\ October 2000
}

We would like to thank Julie Cullen for useful comments on an earlier version of this paper, and Nancy E. Barr and Mary Claire Toomey for help with preparation of the manuscript. The views expressed in this paper are those of the authors and not necessarily those of the National Bureau of Economic Research.

(C) 2000 by John Bound and Timothy Waidmann. All rights reserved. Short sections of text, not to exceed two paragraphs, may be quoted without explicit permission provided that full credit, including $\odot$ notice, is given to the source. 
Accounting for Recent Declines in Employment Rates

among the Working-Aged Disabled

John Bound and Timothy Waidmann

NBER Working Paper No. 7975

October 2000

JEL No. J2, I3

\begin{abstract}
During the 1990s, while overall employment rates for working-aged men and women either remained roughly constant (men) or rose (women), employment rates for the disabled fell. During the same period the fraction of the working-aged population receiving Social Security Disability Insurance (DI) benefits increased quite dramatically. We present simple time series and cross-state evidence suggesting that the growth in the DI program can account for much of the decline in the relative employment position of the disabled.
\end{abstract}

John Bound

Department of Economics University of Michigan

Ann Arbor, MI 48109-1220

and NBER

jbound@umich.edu
Timothy Waidmann

The Urban Institute 2100 M St., NW

Washington, DC 20037

TWaidman@ui.urban.org 


\section{.I. Introduction}

During the 1990s, while overall employment rates for working-aged men and women either remained roughly constant (men) or rose (women), employment rates for the disabled fell. ${ }^{1}$ This period coincided with the introduction of the Americans with Disabilities Act (ADA), which requires employers to offer reasonable accommodation to disabled employees and bans discrimination against the disabled in wage determination, hiring, and firing. Critics of the ADA (Oi, 1991; Rosen, 1991; Weaver, 1991) have argued that because the Act increases the cost of hiring the disabled, it is likely to have negative effects on their employment. ${ }^{2}$ The decline in the employment rates of the disabled since the introduction of the ADA is consistent with this view and several economists (DeLeire, 2000a, 2000b; Acemoglu and Angrist, 1998) have used this evidence to argue for a causal connection between the ADA and the decline in the employment of the disabled.

In this note, we present evidence suggesting that there is an alternative and at least equally plausible explanation for the decline. During the 1990s, the Social Security Disability Insurance (DI) program grew rapidly. Because those who receive DI benefits are effectively precluded from holding jobs, an increase in the proportion of DI beneficiaries among the working-aged disabled could plausibly lead to a concomitant decrease in the relative employment of the disabled.

In the remainder of this note, we document changes in the employment rates of disabled

\footnotetext{
${ }^{1}$ For a discussion of these trends see Burkhauser, Daly and Houtenville (forthcoming).
} 
men and women; discuss the recent growth in the fraction of working-aged disabled who receive DI benefits; and demonstrate the relationship between this fraction and the fraction of workingaged disabled who are out of work. The evidence we present suggests that the expansion of DI during the 1990s played a central role in accounting for the decline in the employment of the disabled during this decade.

\section{Employment Trends in the 1990s}

Figure 1 displays employment rates for disabled and non-disabled men and women. The data used for these tabulations come from the March Current Population Survey (CPS). Employment status is based on the standard recoded labor force status item. Categorization of someone as disabled is based on a question asked as part of the March supplement since 1989: "Does anyone in this household have a health problem or disability which prevents them from working or which limits the kind or amount of work they can do?" The CPS identifies roughly 7 percent of working-aged (16 to 64 years old) men and women as being limited in their capacity to work, with this fraction rising slightly over the period under consideration.

We have chosen to focus our analyses on men and women between the ages of 30-59. We eliminate those under the age of 30 because they are very unlikely to qualify for DI benefits (roughly 3 percent of DI beneficiaries are under the age of 30). We eliminate individuals in their 60 s because, regardless of their health status, many have retired from the work force. Because the fraction of the entire population reporting health limitations and the fraction on DI rises

\footnotetext{
${ }^{2}$ For a more positive view of the potential impact of the ADA see Burkhauser and Daly, 1996.
} 
dramatically with age, we report results separately for three age groups (30-44, 45-54 and 55$59) .^{3}$

Not surprisingly, Figure 1 shows that employment rates among those who do not experience health limitations are substantially higher than among those who do. However, Figure 1 also depicts a striking drop in employment rates during the 1990s among men with limitations-between 10 and 25 percent, depending on the age group examined. Although this trend is less dramatic among women with disabilities, the contrast between the employment growth among able-bodied women and the employment stagnation among women with limitations is quite stark.

Those who are less well educated and members of minority groups are substantially more likely than better-educated whites to suffer health problems and to work in jobs that are physically demanding. Thus, one interpretation of the employment patterns we observe in Figure 1 might be that these reflect educational or racial differences between disabled and non-disabled men and women. To assess the validity of this interpretation, we estimated simple descriptive employment logits, controlling for age, education, and race. Figure 2 displays employment rate differentials (measured in terms of relative odds) between disabled and non-disabled men and women during the 1990s. The top line shows this differential after we control for crude age categories, while the lower line shows the differential after we have added controls for single year of age, education, and race/ethnicity. Not surprisingly, disparities between the disabled and

\footnotetext{
${ }^{3}$ Roughly 6 percent of 30-44 year olds, 9 percent of $45-54$ year olds, and 15 percent of 55-59 year olds are identified as disabled, with the fractions being roughly the same for men and women.
} 
the non-disabled in terms of education and race account for some of the observed employment rate differences between the two groups, but they explain little of the divergent employment trends during the 1990s. These trends show up in data from the Survey of Income and Program Participation (DeLeire, 2000b) and the National Health Interview Survey (National Center for Health Statistics, 2000), as well as the CPS, underlining the need to account for the relative decline in the employment position of the working-aged disabled.

\section{The Recent Growth of the Social Security Disability Insurance Program in Historical}

\section{Context}

The postwar period has seen a dramatic increase both in the availability and in the generosity of income maintenance programs targeted at the disabled. The Social Security Disability Insurance program was enacted in 1956. Originally, individuals could qualify for DI only if they were over the age of 50 and suffered from an impairment that was "expected to result in death or be of long, continued and indefinite duration." In 1960, individuals under the age of 50 were made eligible, and in 1965, the definition of disability was liberalized to allow those without permanent disabilities to qualify. In 1972, the waiting period required before an applicant for DI could start receiving benefits was reduced from 6 to 5 months, and the work history requirement was effectively eliminated with the introduction of Supplemental Security Income (SSI). ${ }^{4}$ At the same time that eligibility requirements for DI were being relaxed, benefit

\footnotetext{
${ }^{4}$ Both DI and SSI are administered by the Social Security Administration. DI provides benefits to disabled workers in amounts related to the disabled worker's former wages in Social Security-covered employment. SSI provides cash assistance for the needy aged as well as to the needy blind and disabled, with no requirement that they have worked in covered employment. As a needs-based program, SSI provides payments based on the amount of other income available to an individual.
} 
levels were being increased, ${ }^{5}$ so that by the mid-1970s typical after-tax replacement rates reached 60 percent.

With these expansions in coverage, the DI rolls grew rapidly during the 1960s and 1970s (see Figure 3). In 1960, 208,000 workers were awarded benefits; by 1975, this figure had risen to 592,000. During the same period, the fraction leaving the rolls each year declined from 20 percent to 13 percent. ${ }^{6}$ With the rising number of awards and a declining termination rate, DI rolls grew to 2.9 million ( 3 percent of the working-age population) by 1980. Total benefits paid out exceeded $\$ 15$ billion, or 20 percent of benefits paid out for retirement. Concern grew during the 1970s that the Social Security Administration was losing control over the system and that many DI beneficiaries might not actually be eligible under the law.

The Social Security Administration first responded to this situation both by trying to refine their regulations guiding decisions, and by negotiating agreements with various states. The consequences were quite dramatic. Eligibility acceptance rates fell from 46.1 to 31.4 percent between 1975 and 1980, with this fall concentrated among states that had been more lenient in their decision making. Then in 1980 Congress passed legislation designed to tighten administrative control over the disability determination process in a number of ways. Importantly, the 1980 law changed both the frequency and the nature of medical eligibility

\footnotetext{
${ }^{5} \mathrm{DI}$ benefits are calculated in essentially the same fashion as Social Security retirement benefits, and have been subject to the same changes in benefit levels.

${ }^{6}$ DI beneficiaries leave the rolls for three reasons. Roughly 15 percent recover and either leave the rolls voluntarily or are terminated after a medical review. Another 35 percent die while on the rolls. The remaining 50 percent are transferred to the retirement program when they reach the age of 65. From 1960 to 1975, the proportions leaving the rolls for each of these three reasons were dropping.
} 
reviews for disability beneficiaries. ${ }^{7}$

The 1980 law had a discernible impact on administrative practice. The number of new awards continued to drop-from .40 to .29 percent of all insured workers between 1980 and 1982. At the same time, there was a five-fold increase in the number of terminations; in two years' time, 25 percent of beneficiaries had their cases reviewed and over 40 percent of those reviewed had their benefits terminated. These stricter practices led to questions about due process. Many who had their benefits terminated during this period won reinstatement on appeal, and concern grew that many of those who did not appeal their terminations were, in fact, eligible for benefits.

Widespread criticism led Congress to further change the law in 1984. These amendments had a profound effect on the standards used to evaluate DI eligibility. First, the burden of proof was shifted onto the Social Security Administration to demonstrate that the health of beneficiaries under review had improved sufficiently to allow them to return to work. Second, a moratorium was imposed on re-evaluations of the most troublesome cases - those that involved mental impairments or pain - until more appropriate guidelines could be developed. Third, benefits were continued for those whose terminations were under appeal. Fourth, more weight was given to source evidence (evidence provided by the claimant's own physician) by requiring that it be considered first, prior to the results of an SSA consultative examination. Fifth,

\footnotetext{
${ }^{7}$ Before 1980 , the only beneficiaries targeted for medical eligibility review were those who had conditions that were likely to improve over time. The new law stipulated that all beneficiaries should periodically go to continuing disability reviews (CDRs), and that all but those deemed to have permanent disabilities should be reviewed every three years. Moreover, as practice had evolved, beneficiaries had not been terminated unless there was evidence of actual improvement. The 1980 law changed this so that the standards used in the CDRs became identical to those
} 
consideration had to be given to the combined effect of all of an individual's impairments, regardless of whether or not any one impairment was severe enough to qualify the individual for benefits. Finally, and perhaps most importantly, the Social Security Administration substantially revised its treatment of mental illness, reducing the weight given to diagnostic or medical factors and emphasizing the ability of an individual to function in work or work-like settings. As Figure 3 illustrates, the 1984 changes had a significant effect on award rates, which rose by roughly 50 percent over the subsequent decade.

Figure 3 also shows the dramatic changes in application rates since 1960. What can explain first the dramatic growth and then the decline and rebound in the application rate for DI? Most obviously, applications seem to mirror changes in eligibility standards, rising when standards were relaxed during the 1960s and early 1970s, falling when standards were tightened in the late 1970s and early 1980s. Application rates appear to have responded more slowly to the relaxation of eligibility standards that occurred in 1984, perhaps because strong economic growth continued through the decade.

\section{Accounting for the Drop in Employment Rates among Disabled Adults}

The longest historical record identifying the disabled comes from the National Health Interview Survey (NHIS). Conducted continuously since 1957 by the National Center for Health Statistics (NCHS), the NHIS provides annual data on a large number of households representing over 100,000 individuals. The NHIS asks individuals whether they consider themselves limited

concurrently being applied when initially evaluating claimants. 
in their ability to perform various activities for reasons of health. Until 1982, all adult respondents were asked whether they were 1) unable to perform their "major activity" due to health problems; 2) limited in their ability to perform their major activity; and 3) limited in any activity. The questionnaire was structured such that men were always asked about their capacity to perform paid work, while women who identified their major activity as "keeping house" were asked about their capacity to do housework.

Starting in 1982, three changes were implemented (Kovar and Poe, 1985). First, the question asking respondents to identify their "major activity" was changed so that men and women had the same list of alternatives from which to choose (working, keeping house, going to school, or something else). Second, regardless of what was identified as their major activity, all individuals under the age of 70 were asked specifically about their ability to work. Third, those who did not report that working was their major activity were asked a set of follow-up questions that allowed construction of a work-limitation response. For working-aged men, the proportion identified as limited or unable to do their major activity and the fraction identified as limited or unable to work are virtually identical. For women, however, the differences are significant.

The survey underwent a major redesign again in 1997. For our purposes, the changes that matter are those in the questions for activity limitation and employment. Although the activity limitation questions were designed to be similar to those asked prior to 1997 , question wording did change somewhat. In addition, the employment questions changed so that responses are not comparable to those prior to the redesign (National Center for Health Statistics, 2000). 
Micro data from the survey are currently available from 1969 through 1997. Given the major redesigns of the NHIS in 1982 and 1997, we restrict attention to the 1969-1996 period for men and 1982-1996 for women. Figure 4 displays for men aged 30-44, 45-54, and 55-59 the fractions identified in the NHIS as: (1) unable to work; (2) limited in their ability to work; (3) both limited in their ability to work and out of work, and (4) receiving DI benefits. ${ }^{8}$ The fraction identified as unable to work and the fraction identified as limited and out of work track each other very closely. This should hardly be surprising. It seems highly unlikely that men who are, in fact, working would report themselves as unable to do so. It also seems likely, given social norms, that men who are out of work and suffer serious health problems would identify themselves as not merely limited in the kind or amount of work they can do but as unable to work altogether.

We also see a reasonably close relationship between the fraction of men who are limited and out of work and the fraction receiving DI benefits. During periods when DI coverage was expanding rapidly, the fraction of men identified as limited and out of work rose. During the late 1970s and early 1980s when the size of the DI population shrank, so did the fraction of men identified as limited and out of work. To gauge the extent to which the growth in the fraction of men receiving DI benefits can account for the growth in the fraction of men identified as unable to work, we first estimated simple linear regressions of the fraction of men who are limited and out of work on the fraction receiving DI benefits, using data from 1969-1989. We then used these models to predict the fraction limited and out of work from 1990-1996. Results are

\footnotetext{
${ }^{8}$ The measures of limitation we present are inclusive, i.e., the fraction "limited" in their ability to work includes both
} 
graphed in Figure 5. Given the growth in the size of the DI population, our projections led us to expect an increase in the fractions limited and out of work of $0.7,1.3$ and 2.5 percentage points for men aged 30-44, 45-54 and 55-59, respectively. As the plots make clear, these increases mirror closely the actual increases during this period.

Figure 6 displays disability status and DI participation for women in the same three age groups examined for men in Figure 4. Roughly the same fraction of women as men are identified as suffering a limitation in their capacity for work. However, a somewhat larger fraction of women than men identify themselves as either unable to work, or as limited and out of work. The latter pattern is consistent with the notion that working-aged women are less firmly attached to the work force than are comparably-aged men, but could also be explained by differences between men and women in terms of their health or the kinds of jobs they hold. Women are less likely than men to receive DI benefits, though this discrepancy has been decreasing. While the fraction of women identified as limited and out of work rose during the 1990s, a period of time during which the fraction of women receiving DI benefits was also rising, the fraction limited and out of work fell during the 1980s despite the fact that the fraction receiving DI benefits was rising during this period of time also. Thus, unlike the pattern found for men, changes in the fraction of women limited and out of work do not seem to track the fraction receiving DI.

What might explain the very different patterns we find for men and women? Employment rates for women were increasing dramatically over the time period under consideration. This trend worked to increase the fraction of women eligible for DI benefits. This 
trend is, presumably, in large part responsible for the secular increase in the fraction of women receiving DI benefits. At the same time, it seems likely that the factors leading to the increase in the overall employment rate among women would have, ceteris paribus, led to increases in employment among women experiencing health limitations. Due to the presence of strong secular trends for women, it is impossible to use the simple time series evidence on women to make inferences about the impact of changes in the medical eligibility standards used to evaluate DI applicants on the employment of women suffering health limitation on their capacity for work. It seems entirely possible that while the factors leading to secular increases in the employment of women were the dominant factor influencing the behavior of disabled women during the 1980s, the growth in the availability of DI benefits represented the dominant factor during the 1990s. Thus, the time series evidence on women seems to indicate that the growth in availability of DI benefits over the past 15 years had a negative effect on the employment rates for disabled women. However, given the various factors at work, it is much more difficult to be confident about the importance of DI when interpreting trends for women than it is for men.

During the 1990s, there was considerable cross-state variation in the growth of the DI population (Stapleton, Coleman, and Dietrich, 1995). Some of this variation might be explained by the differential impact on state economies of the recession in the early 1990s, but it might also be explained by other local factors, including cross-state differences in the administration of the DI award process. Cross-state variations allow us to further study the impact of changes in the availability of DI benefits on changes in the fraction of the population that is limited and out of work. The Social Security Administration publishes the number of individuals receiving DI 
benefits by state and year. We used this information, together with published estimates from the Census Bureau on the size of the resident population in each state, to calculate the fraction of the 16-64 year-old population in each state receiving DI benefits from1989 through 1999 (U.S.

Census Bureau, 1990; 2000). ${ }^{9}$ We used the Current Population Survey to estimate for the same years the fraction of the 16-64 year-old population that was both limited and out of work. We then estimated regressions of the fraction limited and out of work on the fraction receiving DI, including state-fixed effects, allowing us to see how the former rises with the latter.

Results are reported in Table 1. We report both unweighted and weighted results, with the weighted results representing the average share of the 16-64 year-old population in each state. In columns (1) and (3) we report results where the only controls are for state. In columns (2) and (4) we report results based on specifications that also include year effects. In the second panel of the Table, we report results based on log-log specifications. Estimates in the top panel range from 0.72 to 1.05 , suggesting a nearly one-to-one association between changes in the fraction of the working-aged population on DI and changes in the fraction identified as limited and out of work. Estimates in the bottom panel range from 0.43 to 0.57 , suggesting that a 10 percent increase in the fraction of the working-aged population on DI is associated with an approximate 5 percent increase in the proportion of the limited, out of work population. Because considerably less than 50 percent of the population that is limited and out of work receives DI benefits, these two sets of results are consistent with each other.

\footnotetext{
${ }^{9}$ In these tabulations we focus on this wider age range because the state-level data published by the Social Security Administration does not distinguish disabled worker beneficiaries by age or gender.
} 
These estimates imply that the rise in the fraction of the working-aged population receiving DI benefits during the 1990 s can account for all of the rise in the fraction of the same population that reports health limitations and is out of work. According to the CPS, the fraction of the 16-64 year-old population that is identified as limited and out of work rose 18 percent between 1989 and 1999 , from 0.048 to 0.057 . In the same period, the fraction of this population on DI rose 53 percent from 0.018 to 0.028 . Applying the coefficients from the bottom panel of Table 1 to these changes, we calculate that the increase in the fraction of the working-aged population receiving DI benefits can account for more than 100 percent of the observed change. ${ }^{10}$

\section{Discussion}

The evidence we have presented suggests a virtual one-to-one association over the 1990s between the growth in the fraction of the working-aged population receiving DI benefits and the growth in the fraction of the same population that identifies itself as health-limited and out of work. The tight association between these two series clearly suggests that the movement of men and women in relatively poor health out of the labor force and onto disability rolls--a phenomenon we have previously referred to as the earlier accommodation of health limitations (Bound and Waidmann, 1992)--accounts for much of the decline in the work force participation of these men and women during the 1990s. ${ }^{11}$ It is much more difficult to gauge the extent to which this earlier accommodation of health limitations can be causally attributed to the

\footnotetext{
${ }^{10}$ If we take these coefficients literally, the implication is that, were it not for the increase in the fraction of the population receiving DI benefits, the fraction limited and out of work would actually have declined. This counterfactual assumption is not as implausible as it might seem. As we have seen, employment rates for women continued to rise dramatically over this period, while those for men remained roughly constant. Had employment rates for the disabled followed a similar course, overall employment rates for this group would have improved.

${ }^{11}$ For women, underlying changes in work force attachment make it hard to know the extent to which those moving
} 
(exogenous) growth in the availability of DI benefits as opposed to other forces that may have been at work in the 1990s (e.g., a drop in the demand for older, less-skilled workers in poor health). Even if the original impetus for labor force withdrawal came from something other than changes in the availability of disability benefits, it would not be too surprising if those in relatively poor health, faced with relatively poor job prospects, but the possibility of generous early retirement benefits, would have found applying for DI benefits attractive.

At the same time, it seems clear that the increases in the availability of disability benefits did play an important causal role in explaining the growth in both applications and awards during the early 1990s. As discussed, the Social Security Administration introduced dramatic changes in the criteria used to evaluate DI applicants during the 1980s, and a large part of the increase in awards that occurred between the mid-1980s and the early 1990s can be attributed to these changes. ${ }^{12}$ Indeed, the very fact that award rates were rising at the same time that application rates were rising suggests an important role for changes in screening stringency. Alternative explanations for the rise in awards that focus on factors shifting the demand for DI benefits, such as the early 1990's recession or the introduction of the ADA, would suggest that those applying

onto the DI rolls might have been working had they not been on DI.

${ }^{12}$ There has been a considerable amount of government-sponsored work explaining the recent dramatic growth in DI. A good summary of this work can be found in Rupp and Stapleton (1995). Much of this analysis has used statelevel data on applications and awards, giving researchers considerable access to variables that vary across states. Using cross-state data from 1988-1992, Stapleton, Coleman, and Dietrich (1995) (see also Stapleton and Dietrich, 1995 and Stapleton, Coleman, Dietrich and Livermore, 1998) find convincing evidence that the recession of the early 1980s contributed importantly to the rapid rise in the number of applications for DI benefits. They also provide strong, if indirect, evidence that recent changes in screening stringency played a central role in explaining program growth. Moreover, they find that changes in the unemployment rate, together with other factors they include in their models, could explain almost all of the growth in applications for impairments related to conditions of internal organs, but could account for much less of the growth in applications for impairments related to musculoskeletal or mental health conditions. These patterns suggest that regulatory changes such as the increased weight given to pain and other symptoms, the increased reliance on source evidence, and the broadening of the standards used for those 
for disability benefits in the 1990s were more marginally disabled than their counterparts in earlier decades. Without adjustment in the availability of benefits to accommodate the increase in the number of applicants, we would have seen acceptance rates drop.

We also believe that the evidence quite clearly suggests the growth in the availability of disability benefits has played an important causal role in, at minimum, facilitating the withdrawal of disabled men and women from the work force. What plausibly are largely exogenous changes in the availability of benefits -- liberalization through the mid-1970s, retrenchment through the mid-1980s and, since then, liberalization -- have been associated with changes in the fraction of working-aged individuals receiving DI benefits that closely mirror change in the fraction that identify themselves as disabled and out of the work force. This evidence does not preclude the possibility that other factors such as the recession or the introduction of the ADA also played some causal role explaining the drop in the (relative) employment of disabled men and women during the 1990s. However, the evidence we have presented would certainly seem to suggest that changes in the availability of DI benefits--changes that were, themselves, due to changes in the criteria used to evaluate those applying for such benefits--were central for explaining the growth in the fraction of disabled men and women on DI and out of work.

While the evidence we have presented does suggest that the increased availability of disability transfers during the 1990s played a role in inducing or at least facilitating the labor force withdrawal of disabled men and women, this does not necessarily imply that the shift in the criteria used to screen disability insurance applicants was a mistake. There has been a tendency

with mental impairments all have contributed importantly to the recent surge in applications for DI. 
in the literature to equate the behavioral responses to the availability of disability benefits, i.e., changes in work force attachment, to malingering (Parsons 1980a, 1980b; Leonard 1986; Baily 1987; Yelin 1986, 1989). According to this argument, being disabled implies being unable to work, and for those truly unable to work changes in the availability of disability benefits should have no impact on labor force behavior. As a result, researchers who have been interested in defending disability insurance as sensible social policy have been forced into arguing that behavioral responses have been trivial, while taking solace in the fact that those receiving disability transfer income do, indeed, suffer from documentable chronic conditions. Others have taken evidence in favor of behavioral responses as evidence that many of those receiving disability benefits are perfectly capable of work: that the social costs of disability transfers have been high and the target efficiency low.

We have previously argued (Bound and Waidmann, 1992) for an alternative view. The evidence suggests that most of those who apply for disability transfers suffer from potentially disabling conditions. Moreover, a high fraction of those identifying themselves as disabled receive either DI or SSI, and while there are legitimate questions about the validity of the medical screening required to qualify for such benefits, it seems very unlikely that an individual would qualify without suffering from a disabling chronic condition. Still, an individual suffering from disabling conditions is likely to want to try to continue to work unless alternative sources of income are available. To understand the extent to which the availability of disability insurance "distorts" behavior, we need to understand the extent to which any behavioral changes associated with the increased availability of disability benefits were a result of the restriction on work effort 
imposed on DI recipients. Behavioral changes that would have occurred simply as a result of the increased economic resources available to those awarded DI benefits do not represent a distortion. ${ }^{13}$ Evaluating the appropriateness of the changes in the availability of disability benefits that occurred during the 1990s is a much more difficult and complex task than simply estimating the magnitude of the behavioral response to the liberalization that occurred.

There is, however, quite clear evidence that the economic impact of the increased availability of disability insurance during the 1990s was less than it would have been had the individuals induced to leave the work force been able-bodied. Simple tabulations using CPS data show that even among those employed, hours worked and dollars earned by those identified as disabled are substantially less than the hours and earnings of those identified as able-bodied. Perhaps more to the point, Autor and Duggan (2000) have estimated that increases in the availability of disability insurance over the 1990s contributed to the reduction in the overall unemployment rate that occurred over the decade.

\footnotetext{
${ }^{13}$ Presumably DI will have both income and substitution effects on labor supply. Any analysis of the welfare implications of the program needs to distinguish between the two.
} 


\section{References}

Autor, David and Mark Duggan. 2000. "Disability Recipiency and the Decline in Unemployment," paper presented at the National Bureau of Economic Research Summer Institute, Cambridge, MA, August, 2000.

Acemoglu, D. and Joshua Angrist. 1998. "Consequences of Employment Protection: The Case of the Americans with Disabilities Act," National Bureau of Economics Working Paper \# 6670 .

Baily, Martin N. 1987. "Aging and the Ability to Work: Policy Issues and Recent Trends," Work, Health and Income among the Elderly, Gary Burtless, ed. (Washington, DC: The Brookings Institution.

Bound, John, "The Health and Earnings of Rejected Disability Insurance Applicants, 1989. " American Economic Review, LXXIX, 482-503.

Bound, John and Timothy Waidmann. 1992. "Disability Transfers, Self-Reported Health, and the Labor Force Attachment of Older Men: Evidence from the Historical Record," Quarterly Journal of Economics, 107(4): 1393-1419.

Burkhauser, Richard V. and Mary C. Daly. 1996. "The Potential Impact on the Employment of People with Disabilities." In Jane West (ed.), Implementing the Americans with Disabilities Act. Cambridge, MA: Blackwell Publishers, pp. 153-192.

Burkhauser, Richard V. and Mary C. Daly, Andrew J. Houtenville. Forthcoming, "How Working Age People With Disabilities Fared Over the 1990s Business Cycle," in Peter Budetti, Janice Gregory, and Richard Burkhauser (eds.), Ensuring Health and Income Security for an Aging Work Force: 12th Annual Conference of the National Academy of Social Insurance, Kalamazoo, MI: W.E. Upjohn Institute for Employment Research.

DeLeire, Thomas. 2000a. "The Unintended Consequences of the Americans with Disabilities Act." Regulation 23(1): 21-24 . 2000b. "The Wage and Employment Effects of the Americans with Disabilities Act," Journal of Human Resources, 35.

Kovar, M. G., and R. A. Wright. 1973. "An Experiment with Alternate Respondent Rules in the National Health Interview Survey," 1973 Social Statistics Section, Proceedings of the American Statistical Association, 311-16. 
Kovar, M.G., and G. S. Poe. 1985. "The National Health Interview Survey Design, 1973-84, and Procedures, 1975-83." Vital and Health Statistics, series 1, no 18. Washington: National Center for Health Statistics.

Leonard, Jonathan S. 1986. "Disability System Incentives and Disincentives for the Disabled," Disability and the Labor Market: Economic Problems, Policies and Programs, Monroe Berkowitz and M. Anne Hill, eds. (Ithaca, NY: ILR Press).

National Center for Health Statistics. 2000. “1997 National Health Interview Survey (NHIS) Public Use Data Release: NHIS Survey Description.” Hyattsville, MD, February 2000. (ftp://ftp.cdc.gov/pub/Health_Statistics/NCHS/Dataset_Documentation/NHIS/1997/ srvydesc.pdf)

Oi, Walter Y. 1991. "Disability and a Workfare-Welfare Dilemma." In Carolyn L. Weaver (ed.), Disability and Work: Incentives, Rights, and Opportunities. AEI Studies No. 516. Washington, DC: AEI Press, pp. 31-45.

Parsons, Donald O. 1980a. "The Decline of Male Labor Force Participation, " Journal of Political Economy, LXXXVIII, 117-34.

. 1980b. "Racial Trends in Male Labor Force Participation," American Economic Review, LXX, 911-920.

Rosen, Sherwin. 1991. "Disability Accommodation and the Labor Market." In Carolyn L. Weaver (ed.), Disability and Work: Incentives, Rights, and Opportunities. AEI Studies No. 516. Washington, DC: AEI Press, 18-30.

Rupp, Kalman and David C. Stapleton. 1995. "Determinants of the Growth in the Social Security Administration's Disability Programs: An Overview," Social Security Bulletin, 58(4)(Winter): 43-70.

Stapleton, David C., Kevin A. Coleman, Kimberly A. Dietrich, and Gina A. Livermore. 1998. "Econometric Analyses of DI and SSI Application and Award Growth." In Kalman Rupp and David C. Stapleton (eds.), Growth in Disability Benefits: Explanations and Policy Implications. Kalamazoo, MI: W.E. Upjohn Institute for Employment Research, 31-92.

Stapleton, D., K. Coleman, and K. Dietrich. 1995. "Demographic and Economic Determinants of Recent Application and Award Growth for SSA's Disability Programs." Paper presented at the conference, "The Social Security Administration's Disability Programs:

Explanations of Recent Growth and Implications for Disability Policy," sponsored by the Social Security Administration and the Office of the Assistant Secretary for Planning and Evaluation, U.S. Department of Health and Human Services, Washington, DC, July. 
Stapleton, D. and K. Dietrich. 1995. "Long-Term Trends and Cycles in Application and Award Growth." Paper presented at "The Social Security Administration's Disability Programs: Explanations of Recent Growth and Implications for Disability Policy," sponsored by the Social Security Administration and the Office of the Assistant Secretary for Planning and Evaluation, U.S. Department of Health and Human Services, Washington, DC, July.

U.S. Census Bureau. 1990. "State Population and Household Estimates, July 1, 1989” Current Population Reports P25-1058. U.S. Government Printing Office, Washington, DC.

U.S. Census Bureau. 2000. "Population Estimates for the U.S., Regions, and States by Selected Age Groups and Sex: Annual Time series, July 1, 1990 to July 1, 1999” Table ST-99-9 (http://www.census.gov/population/estimates/state/st-99-09.txt).

U.S. Department of Health and Human Services. Various years. Social Security Statistical Supplement. Washington, DC: U.S. Government Printing Office.

U.S. House of Representatives, Committee on Ways and Means. Various years. The Green Book. Washington, DC: U.S. Government Printing Office.

U.S. Social Security Administration. Various years. Social Security Bulletin: Annual Statistical Supplement. Washington, DC: U.S. Government Printing Office.

Waidmann, Timothy, John Bound, and Michael Schoenbaum. 1995. "The Illusion of Failure: Trends in the Self-Reported Health of the U.S. Elderly," Milbank Quarterly, 73(2): 253-87.

Weaver, Carolyn L. 1991. "Incentives Versus Controls in Federal Disability Policy." In Carolyn L. Weaver (ed.), Disability and Work: Incentives, Rights, and Opportunities. AEI Studies No. 516. Washington, DC: AEI Press, pp. 3-17.

Yelin, Edward. 1986. "The Myth of Malingering: Why Individuals Withdraw from Work in the Presence of Illness," Milbank Quarterly, LXIV, 622-49. . 1989. "Displaced Concern: The Social Context of the Work-disability Problem," Milbank Quarterly, LXVII, 114-65. 
Table 1: Regressions of fraction limited and not employed on fraction receiving $D I$ benefits

\begin{tabular}{lcccc}
\hline \hline & \multicolumn{2}{c}{ Unweighted } & \multicolumn{2}{c}{ Weighted } \\
\cline { 2 - 5 } Levels & & & & \\
Coefficient & 0.96 & 1.02 & 1.05 & 0.72 \\
$($ Std Err) & $(0.13)$ & $(0.35)$ & $(0.12)$ & $(0.29)$ \\
$R^{2}$ & 0.805 & 0.815 & 0.780 & 0.796 \\
& & & & \\
Logs & & & & 0.47 \\
Coefficient & 0.43 & 0.57 & 0.48 & $(0.27)$ \\
$\quad($ Std Err) & $(0.06)$ & $(0.23)$ & $(0.06)$ & 0.786 \\
$R^{2}$ & 0.785 & 0.792 & 0.775 & \\
& & & & no \\
\hline Time effects & no & yes & & yes \\
\hline \hline
\end{tabular}

Notes: Heteroskedasticity-consistent standard errors adjusted for clustering of observations within states.

Sources: U.S. Social Security Administration (Various years), U.S. Census Bureau (1990, 2000), and authors' tabulations based on (March) Current Population Survey 1989-1999. 
Figure 1: Employment rates, by age, gender, and disability status
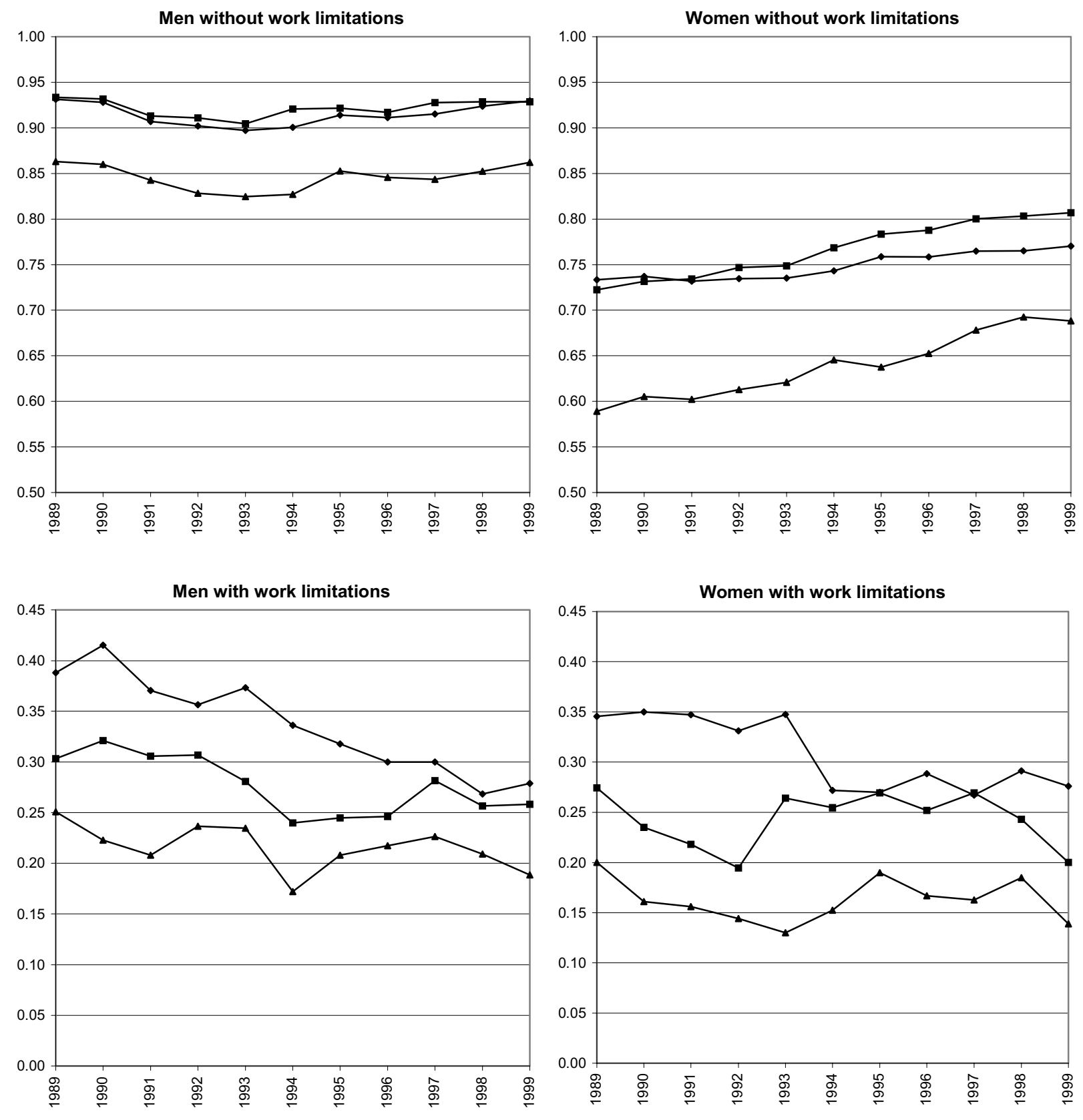

Source: Authors' tabulations based on the (March) Current Population Survey, 1989-1999 
Figure 2: Relative Odds of Employment: Non-disabled vs. disabled
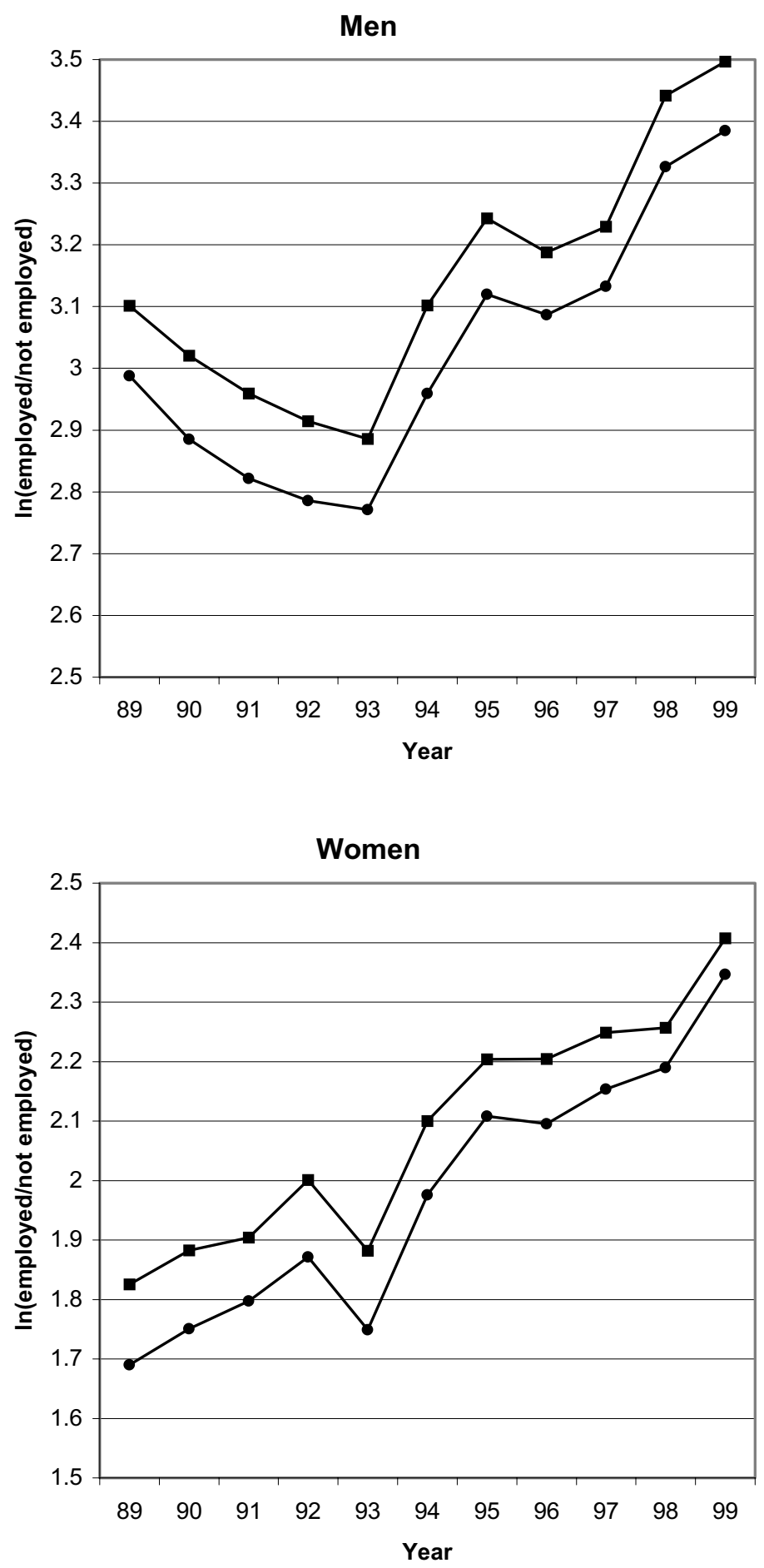

Ln(odds) controlling for $\rightarrow-$ age group

$\rightarrow-$ age, race, education

Source: Authors' tabulations based on (March) Current Population Survey, 1989-1999 
Figure 3: SSDI Applications, Awards and Beneficiaries, 1960-1997

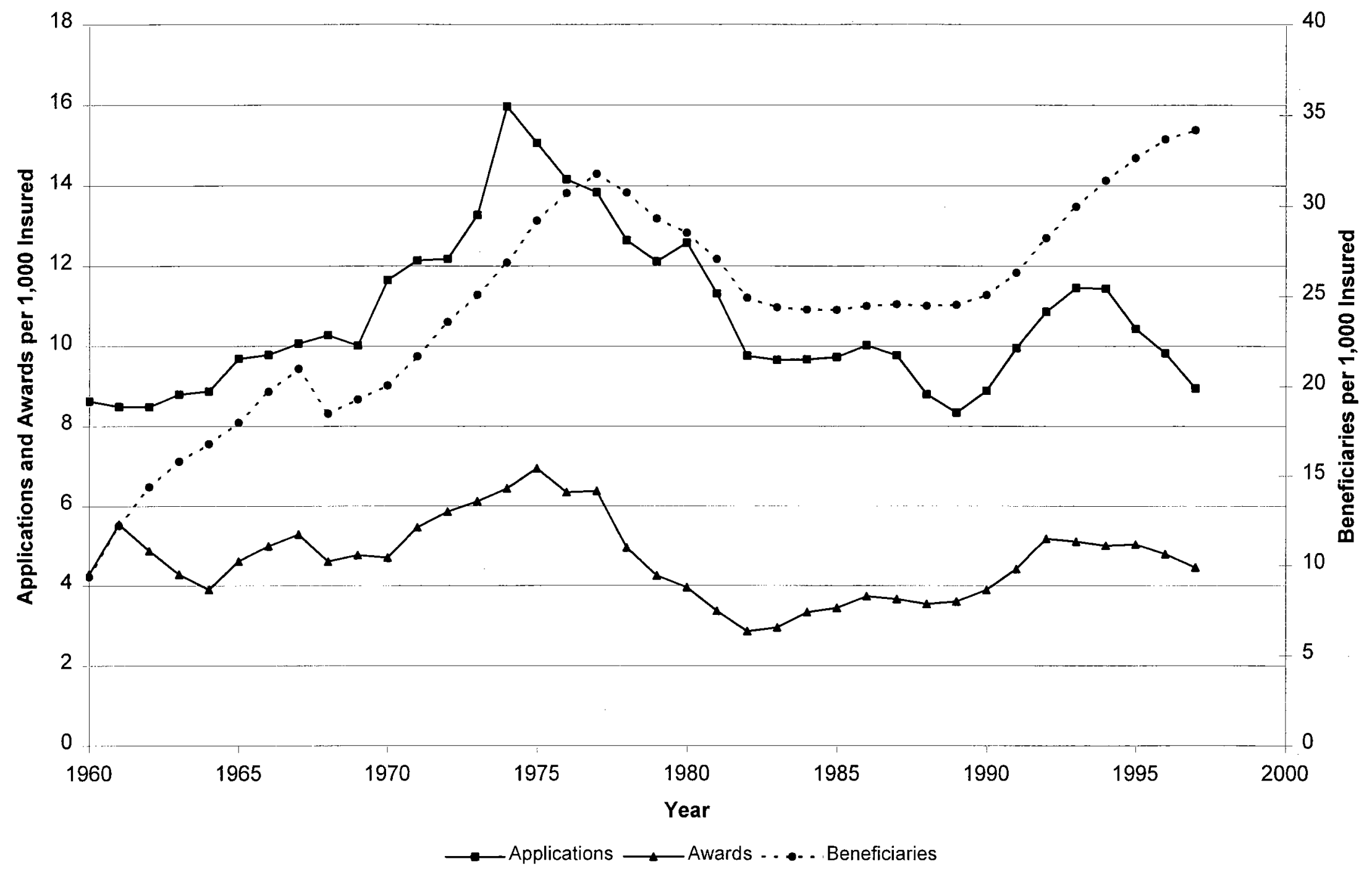

Sources: U.S. Social Security Administration (Various years), U.S. Department of Health and Human Services (Various Years), and U.S. House of Representatives, Committee on Ways and Means (Various years) 
Figure 4: Disability Status and DI Participation, Men 1969-1996

Men 30-44

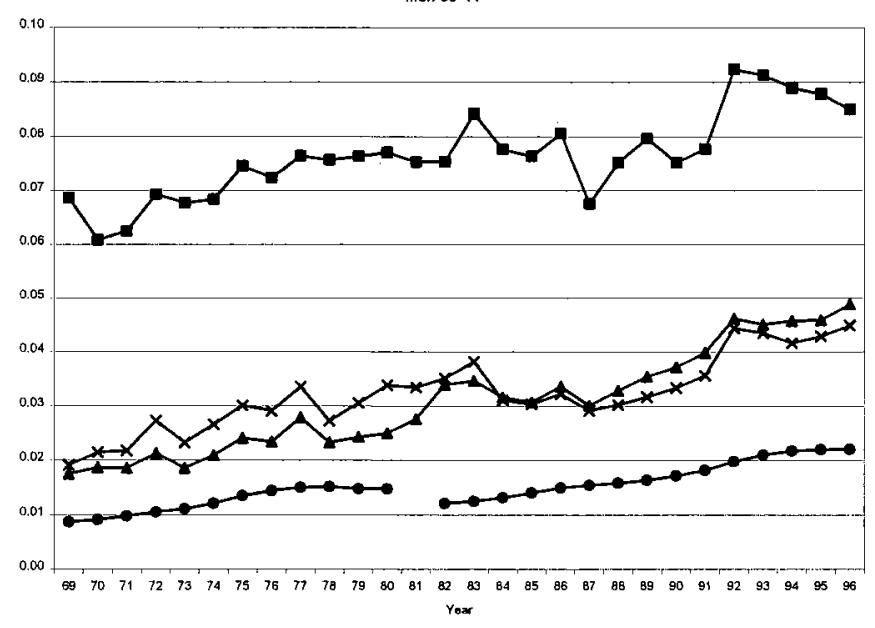

Men, 45-54

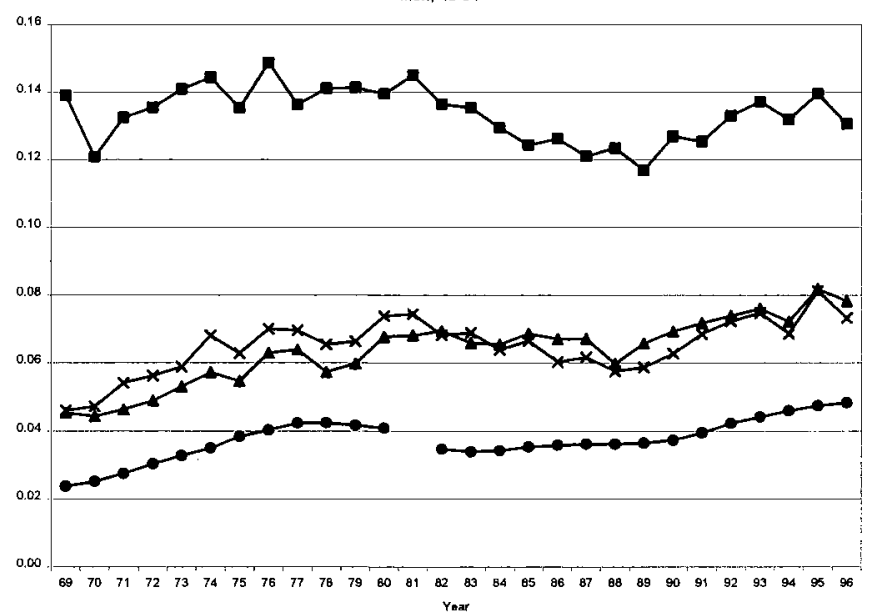

$\operatorname{Men}, 55-59$

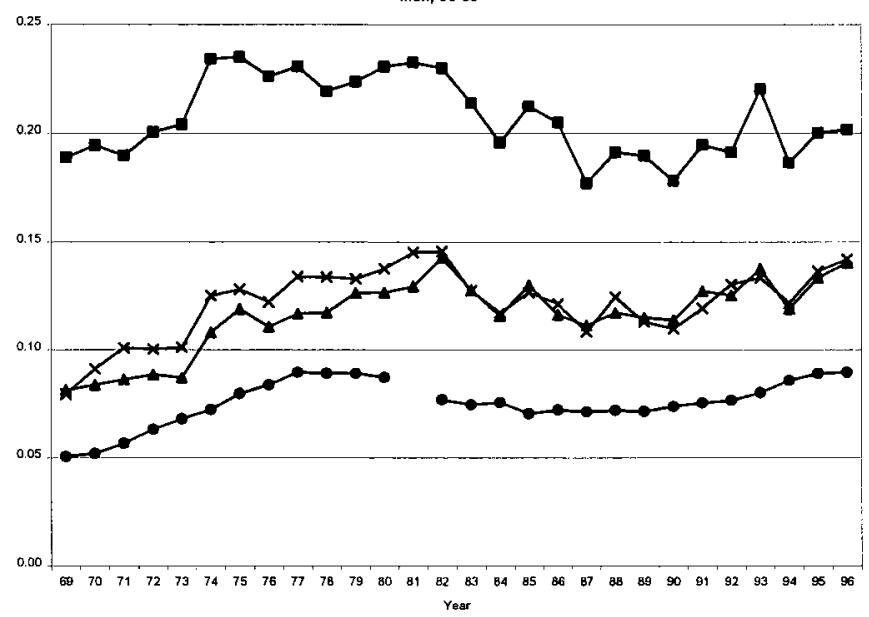

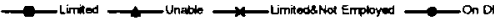

Source: U.S. Social Security Administration (Various Years) and authors' tabulations based on National Health Interview Survey, 1969-1996. 
Figure 5: Fraction of men with work limitations and not employed, and fraction predicted by DI enrollment, 1969-1996

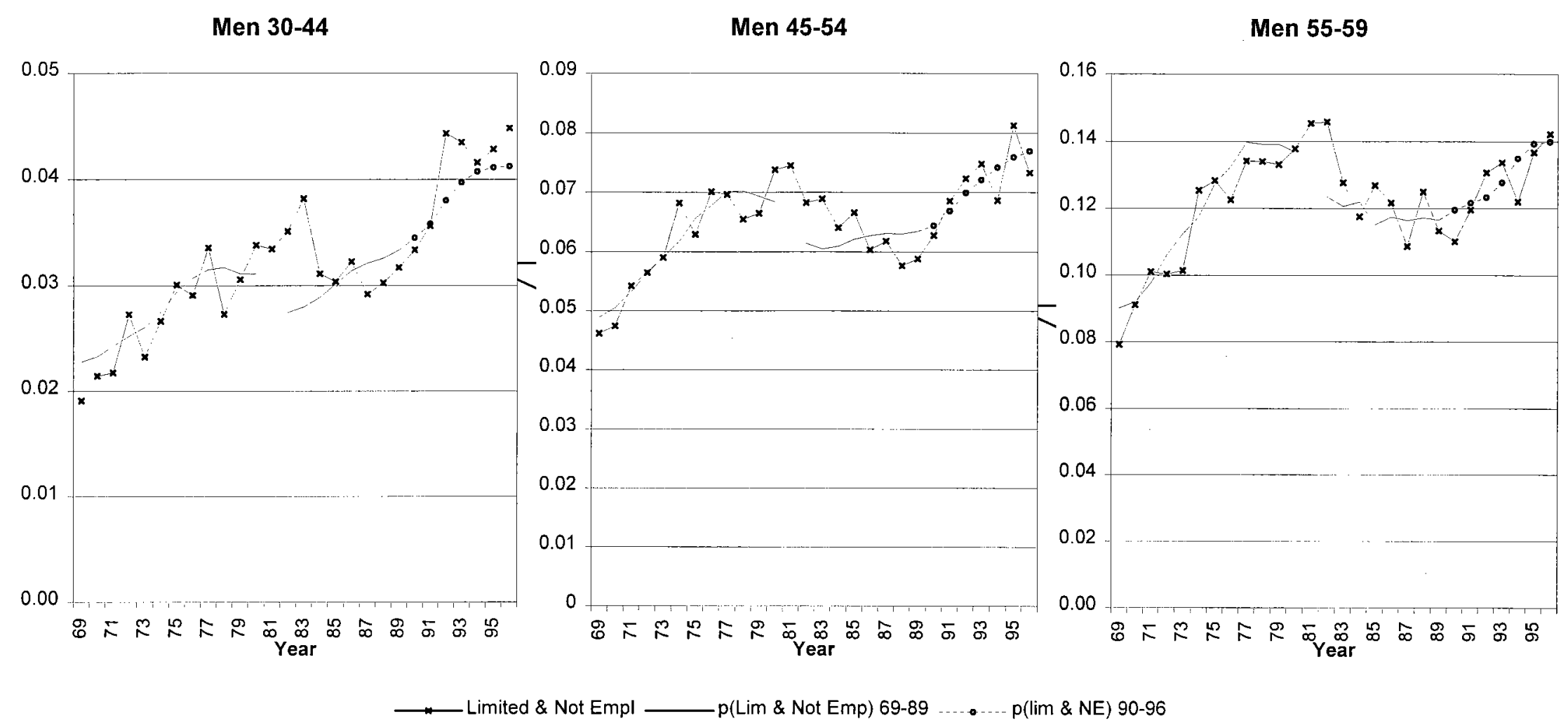

Sources: U.S. Social Security Administration (Various years) and authors' tabulations based on National Health Interview Survey $1969-1996$. 
Figure 6: Disability Status and DI Participation, Women 1982-1996

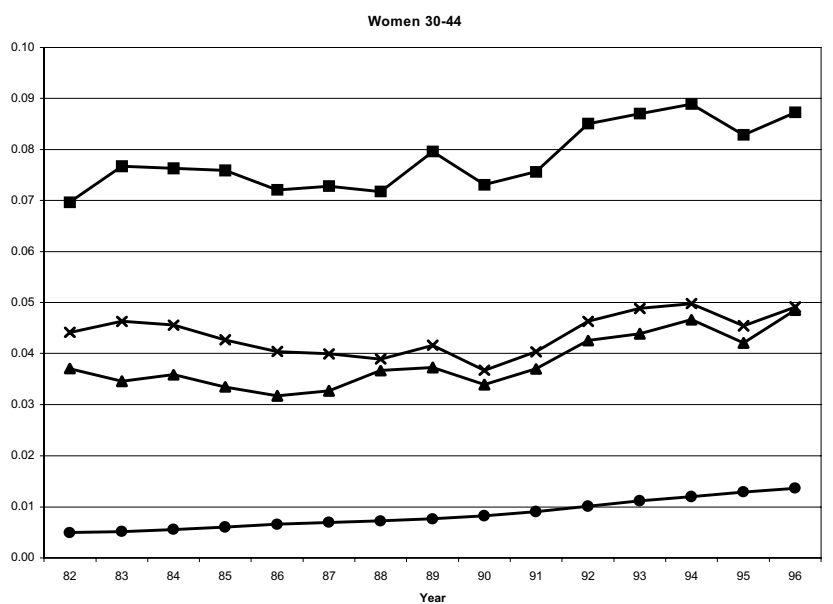

Women, 45-54

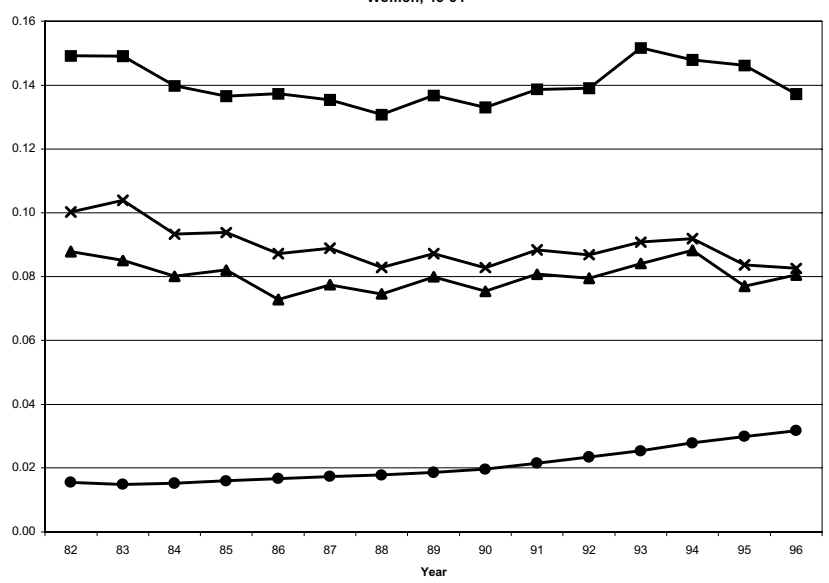

Women, 55-59

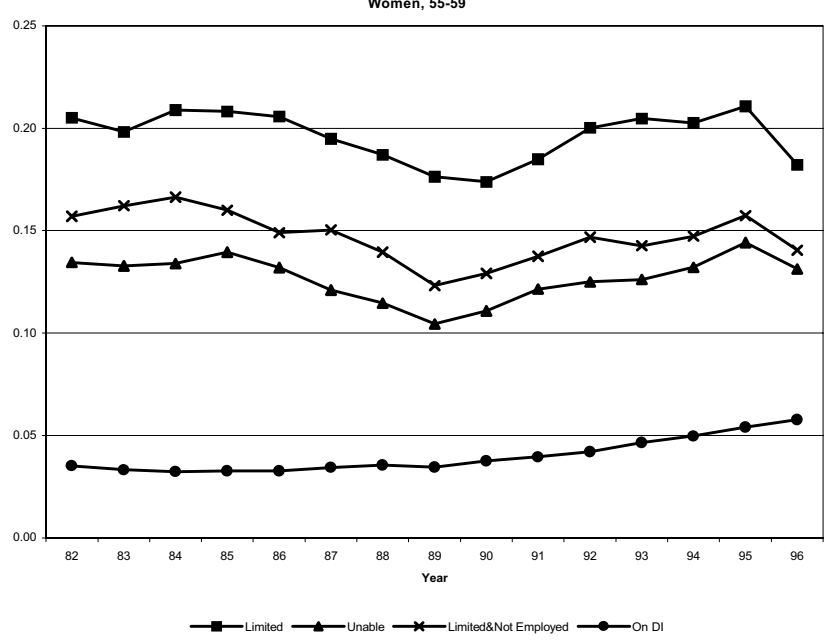

Source: U.S. Social Security Administration (Various Years) and authors' tabulations based on National Health Interview Survey, 1982-1996. 